Mini-Review Open Access

\title{
Regulation of Pathogenesis by Light in Cercospora zeae-maydis: An Updated Perspective
}

\author{
Hun Kim ${ }^{1}$, John B. Ridenour ${ }^{1}$, Larry D. Dunkle ${ }^{2}$ and Burton H. Bluhm ${ }^{1 *}$ \\ ${ }^{1}$ Department of Plant Pathology, University of Arkansas, Fayetteville, AR 72701, USA \\ ${ }^{2}$ Crop Production \& Pest Control Research Unit, USDA-ARS, Purdue University, West Lafayette, IN 47907, USA \\ (Received on November 25, 2010; Accepted on February 25, 2011)
}

\begin{abstract}
The fungal genus Cercospora is one of the most ubiquitous groups of plant pathogenic fungi, and gray leaf spot caused by $C$. zeae-maydis is one of the most widespread and damaging foliar diseases of maize in the world. While light has been implicated as a critical environmental regulator of pathogenesis in C. zeae-maydis, the relationship between light and the development of disease is not fully understood. Recent discoveries have provided new insights into how light influences pathogenesis and morphogenesis in $C$. zeae-maydis, particularly at the molecular level. This review is focused on integrating old and new information to provide an updated perspective of how light influences pathogenesis, and provides a working model to explain some of the underlying molecular mechanisms. Ultimately, a thorough molecular-level understanding of how light regulates pathogenesis will augment efforts to manage gray leaf spot by improving host resistance and disease management strategies.
\end{abstract}

Keywords : Cercospora, photoreceptor, stomatal tropism

Cercospora is one of the world's most ubiquitous genera of plant pathogenic fungi

The fungal genus Cercospora is one of the most diverse and destructive groups of foliar fungal pathogens in the world, comprised of over 3000 named species (Crous and Braun, 2003). Cercospora species infect a wide range of important crops and can cause tremendous losses (Mian et al., 2008; Ward et al., 1999; Weiland and Koch, 2004). Cercospora species are frequently classified according to host association, e.g., C. beticola infects sugar beet (Beta vulgaris). Although Cercospora species generally share many important morphological and biochemical characteristics, the host range of a given species is quite narrow. The fact that such a large number of Cercospora species share numer-

\footnotetext{
*Corresponding author.

Phone) 479-575-2677, FAX) 479-575-7601

E-mail)bbluhm@uark.edu
}

ous physiological characteristics and are closely related at the molecular level (Goodwin et al., 2001), yet exhibit such a high degree of host specificity, seems to indicate that an early progenitor of the taxon evolved a highly effective strategy for foliar pathogenesis that further evolved to overcome defense responses in a wide range of plants.

\section{Cercospora zeae-maydis causes gray leaf spot of maize}

First identified in Illinois in 1924 (Tehon and Daniels, 1925), gray leaf spot did not become a major concern in the U.S. until the 1980s, when a dramatic increase in both incidence and severity was observed (Latterell and Rossi, 1983). In the 1990s, gray leaf spot caused significant losses in the Midwest and, as an endemic pathogen, is now commonly encountered on an annual basis in most maizeproducing regions of the U.S. (Ward et al., 1999). Additionally, during the 1980s and 1990s, the disease also became pandemic throughout Africa and South America, with reported losses of $60 \%$ or greater (Ward et al., 1999). In the U.S., two genetically distinct groups of the pathogen were found to cause identical gray leaf spot symptoms, and were designated Groups I and II (Wang et al., 1998). Later, the two groups were determined to be taxonomically distinct species; Group I retained the species name of $C$. zeaemaydis, whereas Group II was designated C. zeina (Crous et al., 2006). Interestingly, $C$. zeina appears to be the predominant (if not exclusive) gray leaf spot pathogen in Africa (Dunkle and Levy, 2000; Meisel et al., 2009). Both fungi causes distinctive rectangular lesions delineated by major veins of the leaf, and the disease derives its name from the grayish appearance of lesions when masses of conidia are produced on erumpent conidiophores emerging from stomata. When disease pressure is high immediately before or during grain fill, the loss of photosynthetic capacity can substantially reduce yield and predispose plants to other pathogens, such as stalk-rotting fungi. In general, gray leaf spot is most severe in warm, humid conditions; free moisture is critical for disease development (Rupe et al., 1982). 


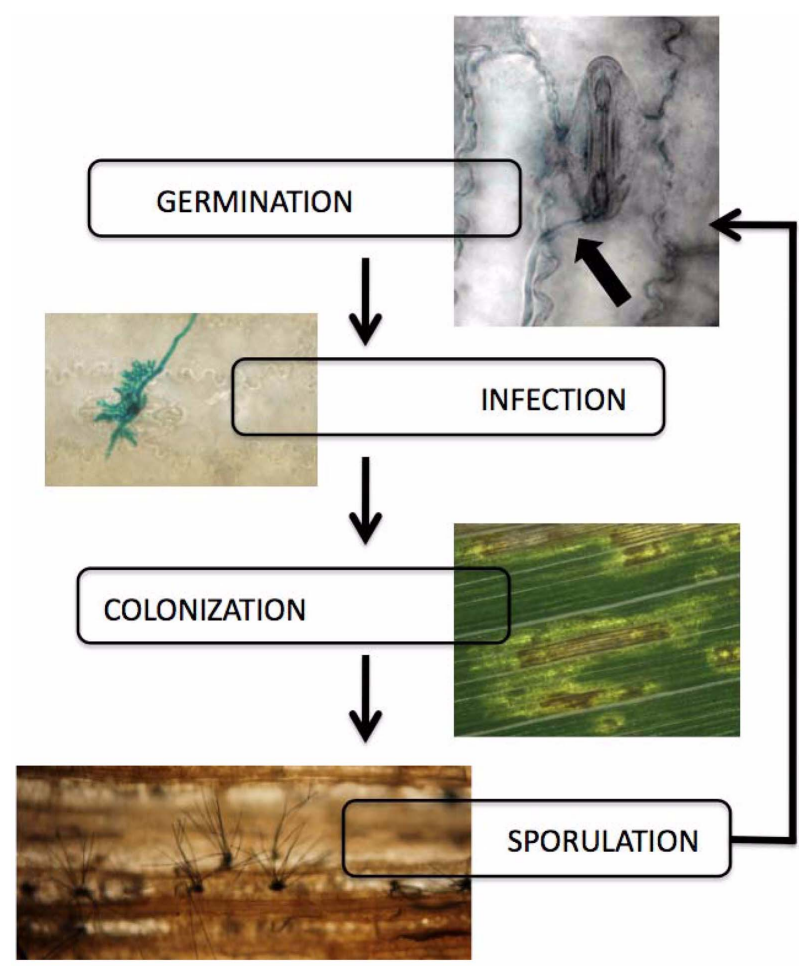

Fig. 1. The disease cycle of gray leaf spot of maize. 1. Germinating spores display stomatal tropism (arrow). 2. Upon reaching stomata, hyphae differentiate into appressoria. 3. After penetrating the leaf, the fungus induces distinctive necrotic lesions. 4. After lesions form, conidiophores emerge through stomata of colonized tissue and produce conidia.

The disease cycle of gray leaf spot can be divided into four distinct stages (Fig. 1). 1. Germination ( $0-3$ days after inoculation [dai]). Asexual spores (conidia) are dispersed onto leaves by wind or rain splash. Under humid conditions, nascent hyphae (germ tubes) emerge and grow across the leaf surface. In the vicinity of a stomate, germ tubes reorient growth to intercept stomata. 2. Infection (3-5 dai). Upon reaching stomata, hyphae differentiate into bulbous, multilobed appressoria. Unlike appressoria produced by Magnaporthe grisea and other fungi that penetrate the epidermis by generating turgor pressure, those produced by C. zeaemaydis appear to function as scaffolds to guide the penetration peg into the stomatal pore. 3. Colonization (5+ dai). After entering the leaf mesophyll via stomata, $C$. zeae-maydis grows intercellularly before switching to a necrotrophic growth habit. The necrotic, expanding lesions induced by C. zeae-maydis are delimited by the major veins of the maize leaf, giving them a distinctive rectangular shape. 4. Sporulation (7+ dai). Shortly after lesions form, erumpent conidiophores emerge through stomatal pores and produce conidia. Often, conidia are produced in a zonate pattern, giving lesions a scalariform (ladder-like) appearance. Conidia are dispersed by wind or water to neighboring plants, thus initiating secondary infection cycles.

Gray leaf spot is difficult to manage because many maize hybrids are moderately to highly susceptible to the disease, the fungus overwinters in plant debris, and until recently, chemical control options were not cost-effective in most regions of the world. Given the increasing reliance on conservation tillage in maize production systems throughout the world and the demonstrated ability of Cercospora species to evolve resistance to numerous fungicide chemistries (Hanson, 2010), the long-term outlook calls for an increased reliance on genetic resistance to ensure effective and sustainable disease management. However, considerably more information is required about the molecular basis of gray leaf spot in order to optimize efforts to improve genetic resistance through conventional breeding or transgenic approaches.

\section{Light regulates secondary metabolism and morpho- genesis in C. zeae-maydis}

During pathogenesis, C. zeae-maydis and many other species of Cercospora produce the non-host-specific phytotoxin cercosporin (Daub and Ehrenshaft, 2000). Cercosporin is a perylenequinone that causes lipid peroxidation and alters membrane permeability by forming reactive oxygen species, thus functioning as a phytotoxin during pathogenesis (Daub and Ehrenshaft, 2000). Of particular importance is the fact that cercosporin biosynthesis is strongly induced by light, although other environmental factors are also involved (You et al., 2008). However, whether cercosporin plays a critical role in gray leaf spot has not been proven conclusively, there is considerable evidence that cercosporin is a broadly conserved, key component of pathogenesis among many Cercospora species. Upchurch et al. (1991) reported that a cercosporin non-producing mutant of $C$. kikuchii, generated by UV mutagenesis, was not able to cause typical necrotic lesions on soybean, and Callahan et al. (1999) demonstrated that $C$. kikuchii requires $C F P 1$, a gene predicted to encode an $\mathrm{ABC}$ transporter, for protection against the toxic effects of cercosporin and virulence on soybean. In C. zeae-maydis, Shim and Dunkle (2003) demonstrated that the disruption of $C Z K 3$, which is predicted to encode a MAP kinase kinase kinase, caused pleiotropic phenotypes, including the abolishment of cercosporin biosynthesis, conidiation, and pigmentation. When inoculated on maize leaves, the $C Z K 3$ disruption mutant failed to elicit typical necrotic lesions, thus implicating CZK3 in virulence. But due to the pleiotropic phenotype of the mutant, it is not conclusive that the reduction in virulence is caused partially or exclusively by the loss of cercosporin biosynthesis. In addition, a cluster of genes involved in cercosporin biosynthesis were recently identified and characterized (Chen et al., 2007a and b; Choquer et al., 2007; Dekkers et al., 2007). However, the 
exact mechanism through which light regulates cercosporin biosynthesis is still unclear.

Light also regulates aspects of morphogenesis in C. zeaemaydis; constant light inhibits spore germination, germ tube growth and sporulation (Beckman and Payne, 1983). Constant light actually stimulates conidiophore development but inhibits conidia formation (Bluhm et al., 2008), and this observation is consistent with that of Latterell and Rossi (1974). Sporulation of C. zeae-maydis is optimal under diurnal light/dark cycles (Beckman and Payne, 1983). It is possible that light-dependent processes among Cercospora species are circadian, in which molecular clocks entrained by light maintain an endogenous rhythm (Bell-Pedersen et al., 1996). In the soybean foliar pathogen C. kikuchii, conidiation is regulated by light in a manner similar to $C$. zeae-maydis, and hyphal melanization is regulated by an endogenous circadian rhythm (Bluhm et al., 2010). This observation is consistent with the hypothesis that hyaline conidia are presumably more sensitive to UV light than darkly pigmented spores or survival structures, and that harnessing a circadian clock to regulate melanization and/or sporulation could allow fungi to optimize the timing of asexual reproduction to avoid harmful UV light. However, the existence of an endogenous molecular clock in C. zeaemaydis has not been confirmed, and it is not clear to what extent light-dependent regulation of conidiation is conserved among Cercospora species.

\section{Is light a global regulator of pathogenesis in $C$. zeae- maydis?}

The role of light in regulating conidiation and cercosporin biosynthesis raises questions of whether light influences additional components of pathogenesis. We recently discovered that light is required for stomatal tropism and appressorium formation in C. zeae-maydis, and that blue light is specifically required for the induction of cercosporin biosynthesis and the repression of conidiation (Kim et al., unpublished data). At the molecular level, fungal pathogenesis is widely regarded as an intricate and complex genetic regulatory network. In C. zeae-maydis, the involvement of light in numerous stages of pathogenesis strongly suggests that a) light regulates fungal development and this ultimately influences pathogen's ability to infect plants, and b) the mechanisms underlying the perception of light and transduction of the signal are likely to play a central role in the genetic regulatory network underlying pathogenesis.

\section{Known and predicted mechanisms underlying light- regulated pathogenesis in $C$. zeae maydis}

Light is a ubiquitous environmental cue that regulates numerous biologically important processes, and organisms across all kingdoms of life have evolved intricate molecular mechanisms to detect and respond to light (Idnurm and Crosson, 2009). Fungi are no exception, wherein elaborate systems for the detection of light at the molecular level have been characterized (Bahn et al., 2007; Purschwitz et al., 2006). Furthermore, a direct relationship between photoreceptors and pathogenicity has recently been established in fungi (Idnurm and Heitman, 2005; Kim et al., unpublished data; Ruiz Roldán et al., 2008).

How plants and fungi detect light is remarkably different at the molecular level. In plants, blue light has long been known to mediate light-induced responses via two broadly grouped classes of photoreceptors - phototropins and cryptochromes (Purschwitz et al., 2006). Phototropins contain a characteristic flavin-binding domain, the LOV (light oxygen voltage) motif, which imparts the capacity to regulate an array of photoreactive responses (Crosson et al., 2003). In fungi, the best understood category of blue-light photoreceptors is encoded by the well-characterized gene family white collar-1 (wc-1; Dunlap and Loros, 2006; HerreraEstrella and Horwitz, 2007). wc- 1 was initially described in a non-pathogenic ascomycete, Neurospora crassa, wherein it encodes a dual-function photoreceptor/GATA family zinc finger transcription factor WC-1. Additionally, WC-1 interacts with another GATA family zinc finger transcription factor, White Collar-2 (WC-2), via two congruent PerARNT-Sim (PAS) motifs to form the heterodimeric white collar regulatory complex (WCC; Ballario et al., 1996; Lee et al., 2003; Purschwitz et al., 2006). The WCC is essential for virtually all light-mediated responses in $N$. crassa, including circadian rhythmicity, morphogenesis, reproduction, secondary metabolism, and phototropism (Ballario et al., 1998; Dunlap and Loros, 2006; Herrera-Estrella and Horwitz, 2007). To date, genes similar to $w c-1$ have been identified in a number of diverse fungi, including ascomycetes, basidiomycetes, and zygomycetes (Estrada and Avalos, 2008). The identification and characterization of wc-1-like genes has shown the degree of functional conservation, which suggests that the molecular mechanisms underlying responses to light may be at least partially conserved across the fungal kingdom.

Recently, CRP1 of C. zeae-maydis, a homolog to the $N$. crassa $w c-1$, was cloned and functionally characterized (Kim et al., unpublished data). Disruption of CRP1 via homologous recombination virtually abolished the ability of the fungus to form appressoria, even in the presence of stomata. During infection, C. zeae-maydis orients hyphal growth toward host stomata, whereupon the fungus initiates entry into mesophyll tissues by forming appressoria directly over stomatal pores. Hence, the severely reduced ability to form appressoria effectively rendered $C R P 1$ disruption mutants 
apathogenic, illustrating the importance of photoreception for virulence in C. zeae-maydis. Interestingly, disruption of CRP1 did not abolish the production of cercosporin nor fully depress conidiation under blue light. These results suggest that additional, uncharacterized blue-light photoreceptors may exist in C. zeae-maydis.

Cryptochromes, blue-light receptors that function exclusively in signal transduction, have been well-characterized in plants and animals (Lin and Todo, 2005), although much less is known about structurally similar proteins in fungi (Bluhm and Dunkle, 2008; Borkovich et al., 2004; Veluchamy and Rollins, 2008). A recent study identified PHL1, a cryptochrome/6-4 photolyase-like gene in C. zeae-maydis (Bluhm and Dunkle, 2008); disruption of PHL1 abolished photoreactivation after exposure to UV light. Additionally, PHL1 mutants were impaired in the induction of CPD1, a cyclobutane pyrimidine dimer (CPD) photolyase, as $R A D 2$ and $R V B 2$, putative orthologs of genes involved in nucleotide excision and chromatin remodeling during DNA damage repair (Bluhm and Dunkle, 2008). Although PHL1 mutants showed abnormalities in development and secondary metabolism, the disruption of PHL1 had no discernible effect on the ability of the fungus to infect and colonize maize leaves and does not appear to function as a blue-light photoreceptor involved in regulating gene expression (Bluhm and Dunkle, 2008).

Beyond blue-light receptors, the genome of C. zeaemaydis contains a number of genes that encode homologous of red- and green-light photoreceptors in other organisms. A recent study in C. zeae-maydis generated a collection of over 27,500 expressed sequence tags (ESTs) and evaluated their expression under a number of conditions, including response to light (Bluhm et al., 2008). A cluster highly similar to phytochromes was identified (Bluhm et al., 2008). Phytochromes are red/far-red light photoreceptors that have been shown to be important in regulating the transition between sexual and asexual reproduction in a select number of fungi (Blumenstein et al., 2005; Purschwitz et al., 2008). Interestingly, a red light-specific morphological or metabolic phenotype has not been observed in C. zeae-maydis (Bluhm and Dunkle, unpublished data), and the potential role of a red-light photoreceptor in pathogenesis is not clear. In addition, homologs of photoreceptors in higher eukaryotes were identified, including blue-/green-light sensing opsins (Bieszke et al., 1999; Waschuk et al., 2005) and an additional protein sequence sharing similarity with plant bluelight sensing phototropin. Moreover, the study identified a number of putative light-regulated genes, including circadian clock regulated genes (Bluhm et al., 2008). To fully understand the potential roles, if any, of these genes in pathogenesis, functional genomics approaches are needed to define individual gene function in the context of host/ pathogen interactions.

\section{Potential roles of light in host defense against $C$. zeae- maydis}

One of the early focuses in plant pathology research was on investigating the relationship between light and disease, based on the hypothesis that pathogens utilize light to recognize favorable conditions for attack (Colhoun, 1973). As discussed above, a direct relationship between light perception and pathogen virulence has been established. In fact, without light, plants are unable to mount a proper defense response to pathogens (Guo et al., 1993; Lozano and Sequeira, 1970). Recently, progress has been made in model plants to better understand the role of light in regulating a complex network of signaling pathways in response to pathogen invasion (Roden and Ingle, 2009). Transcription of many plant defense genes is regulated in response to light (Griebel and Zeier, 2008; Karpinski et al., 2003). For instance, light is instrumental in inducing plant innate immunity via the salicylic acid (SA) signaling pathway (Roden and Ingle, 2009). Additionally, the induction of plant defense genes is elicited by disruptions in light harvesting, photosynthesis, and/or carbon metabolism caused by pathogen attack (Bechtold et al., 2005). The same response is observed in plants exposed to an increase in light intensity. Interestingly, disruption in these physiological processes due to host-pathogen interactions induce systemic acquired resistance (SAR; Bechtold et al., 2005). However, the specific contribution of analogous responses in maize to infection by $C$. zeae-maydis remains to be determined.

Oxylipins, a diverse family of oxygenated metabolites derived from polyunsaturated fatty acids, regulate numerous physiological important processes in plants (Prost et al., 2005). In the context of this review, oxylipins are most notable as potent regulators of host defense in response to fungal pathogens (Farmer et al., 2003; Prost et al., 2005; Rosahl and Feussner, 2004). In maize leaves, the oxylipin encoding gene, $Z m L O X 10$, is primarily regulated by circadian rythmicity (Nemchenko et al., 2006). Significantly, ZmLOX10 expression parallels the diurnal increase in photosynthesis activity (Nemchenko et al., 2006). This suggests that light may be a key factor involved in the induction of host defense regulators, such as oxylipins, in response to circadian rythmicity.

\section{Future perspectives: Evidence for the coordinated response of host and pathogen to photoperiod?}

In filamentous fungi, biological rhythms regulate primary metabolism, growth and development (Jerebzoff, 1965). Particularly, light-regulated conidiation has been exten- 


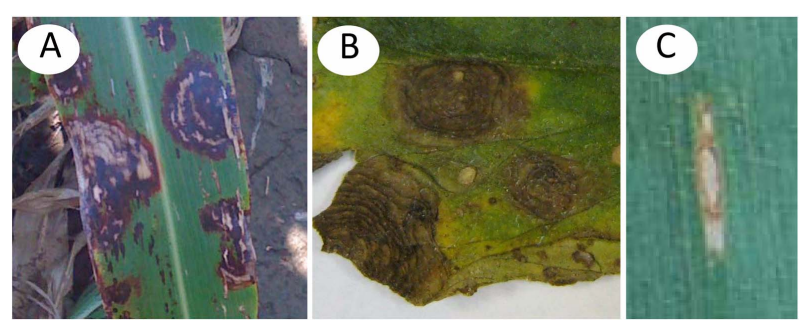

Fig. 2. Rings (concentric or scalariform) radiating from the site of infection are common among fungal foliar diseases. Representative examples include A, zonate leaf spot of sorghum, caused by Gleocercospora sorghi; B, early blight of tomato, caused by Alternaria solani; C, gray leaf spot of maize, caused by C. zeaemaydis.

sively studied in many fungi including Aspergillus and Neurospora. However, the mechanism through which light signals conidiation and how this impacts pathogenesis is unclear.

Although the ability to sense and use light to entrain the innate circadian clock is well established in fungi, a fundamental question remains largely unanswered: why do fungi need to tell time? Considering the predictable, lightdependent daily rhythm of stomatal opening and closing (Shimazaki et al., 2007), our working model is that some fungi use light as a signal to anticipate favorable times for pathogenesis. A tantalizing corollary is the possibility that fungal circadian rhythms regulate infection, i.e., fungi essentially anticipate the predawn opening of stomata. Zonate, concentric rings radiating from the site of infection are quite common among fungal foliar diseases (Fig. 2), and these symptoms could plausibly result from periodicity underlying pathogenesis in either the host or the pathogen.

If our working model is correct, it could have implications for host resistance improvement through both conventional breeding and transgenic approaches. For example, altering or removing the cyclic nature of host defense responses could improve resistance against specific categories of fungal foliar pathogens. Also, genetic screens to identify new sources of resistance could be specifically developed against stomatal tropism and early infection events, which typically cannot be identified in field-level screens for resistance. Furthermore, better molecular understanding of pathogenesis could improve disease management strategies. One possibility is the development of chemicals that can specifically inhibit stomatal tropism in fungi; it could conceivably be applied at a specific point in the day when the pathogen is known to be predisposed to sensitivity.

In conclusion, the importance of light in the complex relationship of plant, pathogen, and photoperiod is becoming increasingly evident. However, despite recent advances in elucidating the complexity in such interactions, the underlying molecular mechanisms and signaling pathways remain poorly understood. Future efforts focusing on the molecular dissection of light-dependent components of fungal virulence and plant defense are required to gain a full appreciation of how light influences the development of plant diseases.

\section{Acknowledgements}

The authors are grateful for financial support from USDAARS CRIS project 3602-22000-015-00D (L. Dunkle), and NSF award 0920287 (B. Bluhm).

\section{References}

Bahn, Y. S., Xue, C., Idnurm, A., Rutherford, J. C., Heitman, J. and Cardenas, M. E. 2007. Sensing the environment: lessons from fungi. Nat. Rev. Microbiol. 5:57-69.

Ballario, P., Vittorioso, P., Magrelli, A., Talora, C., Cabibbo, A. and Macino, G. 1996. White collar-1, a central regulator of blue light responses in Neurospora, is a zinc finger protein. EMBO J. 15:1650-1657.

Ballario, P., Talora, C., Galli, D., Linden, H. and Macino, G. 1998. Roles in dimerization and blue light photoresponse of the PAS and LOV domain of Neurospora crassa white collar proteins. Mol. Microbiol. 29:719-729.

Bechtold, U., Karpinski, S. and Mullineaux, P. 2005. The influence of the light environment and photosynthesis on oxidative signaling responses in plant-biotrophic pathogen interactions. Plant Cell Environ. 28:1046-1055.

Beckman, P. M. and Payne, G. A. 1982. External growth, penetration, and development of Cercospora zeae-maydis in corn leaves. Phytopathology 72:810-815.

Beckman, P. M. and Payne, G. A. 1983. Cultural techniques and conditions influencing growth and sporulation of Cercospora zeae-maydis and lesion development in corn. Phytopathology 73:286-289.

Bell-Pedersen, D., Garceau, N. and Loros, J. J. 1996. Circadian rhythms in fungi. J. Genetics. 75:387-401.

Bieszke, J. A., Spudich, E. N., Scott, K. L., Borkovich, K. A., and Spudich, J. L. 1999. A eukaryotic protein, NOP-1, binds retinal to form an archaeal rhodopsin-like photochemically reactive pigment. Biochemistry 38:14138-14145.

Bluhm, B. H., Burnham, A. M. and Dunkle, L. D. 2010. A circadian rhythm regulating hyphal melanization in Cercospora kikuchii. Mycologia 102:1221-1228.

Bluhm, B. H., Dhillon, B., Lindquist, E. A., Kema, G. H. J., Goodwin, S. B. and Dunkle, L. D. 2008. Expressed sequence tags derived from the maize foliar pathogen Cercospora zeae-maydis identify novel genes differentially expressed during vegetative, infectious, and reproductive growth. BMC Genomics 9:523.

Bluhm, B. and Dunkle, L. D. 2008. Phll of Cercospora zeaemaydis encodes a member of the photolyase/cryptochrome family involved in UV protection and fungal development. Fungal Gen. Biol. 45:1364-1372. 
Blumenstein, A., Vienken, K., Tasler, R., Purschwitz, J., Veith, D., Frankenberg-Dinkel, N. and Fischer, R. 2005. The Aspergillus nidulans phytochrome FphA represses sexual development in red light. Curr. Biol. 15:1833-1838.

Borkovich, K. A., Alex, L. A., Yarden, O., Freitag, M., Turner, G. E., Read, N. D., Seiler, S., Bell-Pedersen, D., Paietta, J., Plesofsky, N., Plamann, M., Goodrich-Tanrikulu, M., Schulte, U., Mannhaupt, G., Nargang, F. E., Radford, A., Selitrennikoff, C., Galagan, J. E., Dunlap, J. C., Loros, J. J., et al. 2004. Lessons from the genome sequence of Neurospora crassa: tracing the path from genomic blueprint to multicellular organism. Microbiol. Mol. Biol. Rev. 68:1-108.

Callahan, T., Rose, M., Meade, M., Ehrenshaft, M. and Upchurch, R. 1999. CFP, the putative cercosporin transporter of Cercospora kikuchii, is required for wild type cercosporin production, resistance, and virulence on soybean. Mol. PlantMicrobe Interact. 12:901-910.

Chen, H. Q., Lee, M. H. and Chung, K. R. 2007a. Functional characterization of three genes encoding putative oxidoreductases required for cercosporin toxin blosynthesis in the fungus Cercospora nicotianae. Microbiology 153:2781-2790.

Chen, H. Q., Lee, M. H., Daub, M. E. and Chung, K. R. $2007 \mathrm{~b}$. Molecular analysis of the cercosporin biosynthetic gene cluster in Cercospora nicotianae. Mol. Microbiol. 64:755-770.

Choquer, M., Lee, M. H., Bau, H. J. and Chung, K. R. 2007. Deletion of a MFS transporter-like gene in Cercospora nicotianae reduces cercosporin toxin accumulation and fungal virulence. FEBS Lett. 581:489-494.

Colhoun, J. 1973. Effects of environmental factors on plant disease. Annu. Rev. Phytopathol. 11:343-364.

Crosson, S., Rajagopal, S. and Moffat, K. 2003. The LOV domain family: photoresponsive signaling modules coupled to diverse output domains. Biochemistry 42:2-10.

Crous, P. W. and Braun, U. 2003. Mycosphaerella and its anamorphs. 1. Names published in Cercospora and Passalora. CBS Biodiversity Series 1:1-571.

Crous, P. W., Groenewald, J. Z., Groenewald, M., Caldwell, P., Braun, U. and Harrington, T. C. 2006. Species of Cercospora associated with grey leaf spot of maize. Stud. Mycol. 55:189197.

Daub, M. E. and Ehrenshaft, M. 2000. The photoactivated Cercospora toxin cercosporin: contributions to plant disease and fundamental biology. Annu. Rev. Phytopathol. 38:461-490.

Dekkers, K. L., You, B. J., Gowda, V. S., Liao, H. L., Lee, M. H., Bau, J. J., Ueng, P. P. and Chung, K. R. 2007. The Cercospora nicotianae gene encoding dual O-methyltransferase and FAD dependent monooxygenase domains mediates cercosporin toxin biosynthesis. Fungal Genet. Biol. 44:444-454.

Dunkle, L. D. and Levy, M. 2000. Genetic relatedness of African and United States populations of Cercospora zeae-maydis. Phytopathology 90:486-490.

Dunlap, J. C. and Loros, J. J. 2006. How fungi keep time: circadian system in Neurospora and other fungi. Curr. Opin. Microbiol. 9:579-587.

Estrada, A. F. and Avalos, J. 2008. The White Collar protein WcoA of Fusarium fujikuroi is not essential for photocaro- tenogenesis, but is involved in the regulation of secondary metabolism and conidiation. Fungal Genet. Biol. 45:705-718.

Farmer, E. E., Almeras, E. and Krishnamurthy, V. 2003. Jasmonates and related oxylipins in plant responses to pathogenesis and herbivory. Curr. Opin. Plant Biol. 6:372-378.

Goodwin, S. B., Dunkle, L. D. and Zisman, V. L. 2001. Phylogenetic analysis of Cercospora and Mycosphaerella based on the internal transcribed spacer region of ribosomal DNA. Phytopathology 91:648-658.

Griebel, T. and Zeier, J. 2008. Light regulation and daytime dependency of inducible plant defenses in Arabidopsis: phytochrome signaling controls systemic acquired resistance rather than local defense. Plant Physiol. 147:790-801.

Guo, A., Reimers, P. J. and Leach, J. E. 1993. Effect of light on incompatible interactions between Xanthomonas oryzae pv oryzae and rice. Physiol. Mol. Plant Pathol. 42:413-425.

Hanson, L. E. 2010. Genetics of Fungicide Resistance in Cercospora and Mycospharella. In: Cercospora Leaf Spot of Sugar Beet and Related Species, ed. by R. T. Lartey, J. J. Weiland, L. Panella, P. W. Crous and C. E. Windels, pp. 179188. APS Press. St. Paul, USA.

Herrera-Estrella, A. and Horwitz, B. A. 2007. Looking through the eyes of fungi: molecular genetics of photoreception. Mol. Microbiol. 64:5-15.

Idnurm, A. and Crosson, S. 2009. The photobiology of microbial pathogenesis. PLoS Pathogens 5:e1000470.

Idnurm, A. and Heitman, J. 2005. Light controls growth and development via a conserved pathway in the fungal kingdom. PLoS Biol. 3:e95.

Jerebzoff, S. 1965. Growth rhythms. In: The Fungi, ed. by G. C. Ainsworth and A. S. Sussman, vol. I, pp. 625. Academic Press, London, UK.

Karpinski, S., Gabrys, H., Mateo, A., Karpinska, B. and Mullineaux, P. M. 2003. Light perception in plant disease defence signalling. Curr. Opin. Plant Biol. 6:390-396.

Latterell, F. M. and Rossi, A. E. 1983. Gray leaf spot of corn: a disease on the move. Plant Dis. 67:842-847.

Lee, K., Dunlap, J. C. and Loros, J. J. 2003. Roles for WHITE COLLAR-1 in circadian and general photoperception in $\mathrm{Neu}$ rospora crassa. Genetics 163:103-114.

Lin, C. and Todo, T. 2005. The cryptochromes. Genome Biol. 6:220-228.

Lozano, J. and Sequeira, L. 1970. Differentiation of races of Pseudomonas solanacearum by a leaf infiltration technique. Phytopathology 60:833-838.

Meisel, B., Korsman, J., Kloppers, F. J. and Berger, D. K. 2009. Cercospora zeina is the causal agent of grey leaf spot disease of maize in southern Africa. Eur. J. Plant Pathol. 124:577583.

Mian, M. A. R., Missaoui, A. M., Walker, D. R., Phillips, D. V. and Boerma, H. R. 2008. Frogeye leaf spot of soybean: A review and proposed race designations for isolates of Cercospora sojina Hara. Crop Sci. 48:14-24.

Nemchenko, A., Kunze, S., Feussner, I. and Kolomiets, M. 2006. Duplicate maize 13- lipoxygenase genes are differentially regulated by circadian rhythm, cold stress, wounding, pathogen 
infection and hormonal treatments. J. Exp. Bot. 57:37673779.

Prost, I., Dhondt, S., Rothe, G., Vicente, J., Rodriguez, M. J., Kift, N., et al. 2005. Evaluation of the antimicrobial activities of plant oxylipins supports their involvement in defense against pathogens. Plant Physiol. 139:1902-1913.

Purschwitz, J., Muller, S., Kastner, C. and Fischer, R. 2006. Seeing the rainbow: light sensing in fungi. Curr. Opin. Microbiol. 9:566-571.

Purschwitz, J., Muller, S., Kastner, C., Schöser, M., Haas, H., Espeso, E. A., Atoui, A., Calvo, A. M. and Fischer, R. 2008. Functional and physical interaction of blue- and red light sensors in Aspergillus nidulans. Curr. Biol. 18:1-5.

Roden, L. C. and Ingle, R. A. 2009. Lights, rhythms, infection: The role of light and the circadian clock in determining the outcome of plant-pathogen interactions. Plant Cell 21:25462552.

Rosahl, S. and Feussner, I. 2004. Oxylipins. In: Plant lipids: Biology, utilisation and manipulation, ed. by D. J. Murphy, pp. 329-354. Oxford: Blackwell Publisher.

Ruiz-Roldan, M. C., Garre, V., Guarro, J., Marine, M. and Roncero, M. I. 2008. Role of the white collar 1 photoreceptor in carotenogenesis, UV resistance, hydrophobicity, and virulence of Fusarium oxysporum. Eukaryot. Cell 7:1227-1230.

Rupe, J. C., Siegel, M. R. and Hartmann, J. R. 1982. Influence of environment and plant maturity on gray leaf spot of corn caused by Cercospora zeae-maydis. Phytopathology 72:15871591.

Shim, W. and Dunkle, L. D. 2003. CZK3, A map kinase kinase kinase homolog in Cercospora zeae-maydis, regulates cer- cosporin biosynthesis, fungal development, and pathogenesis. Mol. Plant-Microbe Interact. 16:760-768.

Shimazaki, K., Doi, M., Assmann, S. M. and Kinoshita, T. 2007. Light regulation of stomatal movement. Annu. Rev. Plant Biol. 58:219-247.

Tehon, L. R. and Daniels, E. 1925. Notes on the parasitic fungi of Illinois. Mycologia 17:240-249.

Upchurch, R. G., Walker, D. C., Rollins, J. A., Ehrenshaft, M. and Daub, M. E. 1991. Mutants of Cercospora kikuchii altered in cercosporin synthesis and pathogenicity. Appl. Environ. Microbiol. 57:2940-2945.

Veluchamy, S. and Rollins, J. A. 2008. A CRY-DASH-type photolyase/cryptochrome from Sclerotinia sclerotiorum mediates minor UV-A-specific effects on development. Fungal Genet. Biol. 45:1265-1276.

Wang, J., Levy, M. and Dunkle, L. D. 1998. Sibling species of Cercospora associated with gray leaf spot of maize. Phytopathology 88:1269-1275.

Ward, J. M. J., Stromberg, E. L., Nowell, D. C. and Nutter, F. W. 1999. Grey leaf spot, a disease of global importance in maize production. Plant Dis. 83:884-895.

Waschuk, S. A., Bezerra, A. G. Jr., Shi, L. and Brown, L. S. 2005. Leptosphaeria rhodopsin: bacteriorhodopsin-like proton pump from a eukaryote. Proc. Natl. Acad. Sci. USA 102:6879-6883.

Weiland, J. and Koch, G. 2004. Sugarbeet leaf spot disease (Cercospora beticola Sacc.). Mol. Plant Pathol. 5:157-166.

You, B. J., Lee, M. H. and Chung, K. R. 2008. Production of cercosporin toxin by the phytopathogenic Cercospora fungi is affected by diverse environmental signals. Can. J. Microbiol. 54:259-269. 